\title{
Erratum to: True-FISP MRI in diagnosis of postoperative hernia recurrence: a brief report
}

\author{
U. Salati · E. Mansour - W. Torreggiani
}

Published online: 24 February 2013

(C) Springer-Verlag France 2013

\section{Erratum to: Hernia}

\section{DOI 10.1007/s10029-012-1038-7}

In the original publication, the acronym US has been inadvertently published incorrectly to read "United States" in the results section of the abstract. The "US" here denotes Ultrasound. The corrected paragraph is given below:

Results: Initial focused ultrasound (US) was suggestive of but equivocal for recurrence. Subsequent non-contrast CT of the region followed by rapid sequence (true-FISP) MRI confirmed the presence of bowel in the inguinal canal.

The online version of the original article can be found under doi:10.1007/s10029-012-1038-7.

U. Salati $(\bowtie) \cdot$ E. Mansour · W. Torreggiani Adelaide and Meath Hospital, Tallaght, Dublin 24, Ireland

e-mail: umersalati@gmail.com

E. Mansour

e-mail: ehab_mansour@yahoo.com

W. Torreggiani

e-mail: William.Torreggiani@amnch.ie 